\title{
La tramitación de la disidencia política en la Buenos Aires rivadaviana
}

\author{
The processing of the political dissidence in the Buenos Aires rivadaviana
}

\author{
Irina Polastrelli \\ iripolastrelli@gmail.com \\ Instituto de Estudios Críticos en Humanidades. \\ Universidad Nacional de Rosario - CONICET, \\ Argentina
}

Recepción: 14 Marzo 2021

Aprobación: 09 Mayo 2021

Publicación: 01 Julio 2021

Cita sugerida: Polastrelli, I. (2021). La tramitación

de la disidencia política en la Buenos Aires

rivadaviana. Trabajos y Comunicaciones, (54),

e152. https://doi.org/10.24215/23468971e152

\begin{abstract}
Resumen: A partir del análisis de los dos episodios protagonizados por Gregorio Tagle y destinados a desestabilizar al gobierno provincial en 1822 y 1823 , este artículo estudia el tratamiento dispensado a quienes fueron catalogados como disidentes durante el período conocido como "feliz experiencia" en Buenos Aires. Para ello se analizan procesos judiciales, debates de la Sala de Representantes, prensa. La intención es marcar contrastes y/o similitudes respecto de la década revolucionaria.

Palabras clave: Disidencia política, Judicialización, Elite, Buenos Aires, "Feliz experiencia".

Abstract: From the analysis of the two episodes starring Gregorio Tagle and destined to destabilize the provincial government in 1822 and 1823, this article studies the treatment given to those who were classified as dissidents during the period known as "feliz experiencia" in Buenos Aires. For this, judicial processes, debates in the Sala de Representantes and press are analysed. The intention is to mark contrasts and/or similarities with respect to the revolutionary decade.
\end{abstract}

Keywords: Political dissidence, Judicialization, Elite, Buenos Aires , "Feliz experiencia".

\section{INTRODUCCIÓN}

Con la caída del Directorio y la disolución del Congreso General Constituyente en 1820 sucumbió el centro revolucionario porteño que durante la década precedente pretendió gobernar el espacio rioplatense. Buenos Aires renunció a ser capital de un extenso territorio ya independiente y se recluyó fronteras adentro con la intención de remediar los estragos causados por los conflictos bélicos y las continuas disputas con el resto de las regiones. La pacificación de la provincia fue acompañada por la instauración de un nuevo ordenamiento político, económico y social que terminó creando una "cuasi unanimidad" en su apoyo. (Halperin, 2005, p. 352) La llamada "feliz experiencia rivadaviana" aglutinó así a un grupo heterogéneo en su origen pero con el objetivo común de clausurar finalmente el periodo de la revolución. La apertura del régimen a la deliberación del cuerpo político y la mayor cohesión de la elite dirigente parecían traducirse en una menor conflictividad durante los años iniciales de la década. (Ternavasio, 1999). Sin embargo, las 
disidencias no tardaron en aparecer. ${ }^{1}$ Al surgimiento de un nuevo clima de debate cada vez más virulento que se encauzó por la prensa periódica, se añadieron dos incidentes destinados a desestabilizar al gobierno provincial. Los movimientos, compuestos por curas de la campaña, políticos y militares que no habían logrado adaptarse a la nueva conformación del poder provincial, constituyeron una reacción contra algunas de las reformas impulsadas por el gobierno de Martín Rodríguez, especialmente por las que trastocaron las corporaciones eclesiásticas y militares. ${ }^{2}$

El 23 de agosto de 1822 el ministro Bernardino Rivadavia presentó a la Sala de Representantes el testimonio del oficial Celestino Vidal que aseguraba que Gregorio Tagle estaba preparando una conspiración para "acabar con la representacion y el gobierno", "nombrar gobernador y dos ministros" y "restablecer la municipalidad estinguida". Según la denuncia, los complotados afirmaban que el gobierno "defraudaba la mayor parte de las rentas", destinándolas “á usos personales” y a "hacerse de prosélitos para entregar este pais á la España”, que los ministros eran "ignorantes" y que trataban de "destruir la religion". ${ }^{3}$ Tagle fue detenido y desterrado sin un juicio previo. La frustrada conjuración pareció tener su revancha meses más tarde: la noche del 19 de marzo de 1823 una "reunión de gente armada", proveniente de las afueras de la ciudad, se congregó en la Plaza de la Victoria vociferando "viva la religion y la patria". Los "conjurados forzaron la guardia de la cárcel y liberaron a varios presos, entre ellos, a José María Urien - “muy afamado por sus címenes”- y se apoderaron de la campana de "la casa de justicia para llamar al pueblo". Pero fueron rechazados en un fugaz enfrentamiento, en el que murieron algunos y otros tantos fueron apresados y luego, juzgados de manera pública y solemne. ${ }^{4}$

A partir del análisis de los dos episodios brevemente reseñados, este artículo se propone trazar un bosquejo del tratamiento dispensado a quienes fueron catalogados como disidentes durante el período conocido como "feliz experiencia" en Buenos Aires. Para ello se analizan procesos judiciales, debates de la Sala de Representantes, prensa periódica. El trabajo se estructura del siguiente modo: el primer apartado se enfoca en los debates desarrollados en la Legislatura con el fin de determinar cómo proceder con el principal implicado en la desbaratada conspiración de 1822, Gregorio Tagle; el segundo aborda los pormenores de la causa militar sustanciada contra Celestino Vidal, el oficial delator del plan; y el tercero indaga la definición de los delitos atribuidos a los acusados de participar tanto en la conjura de 1822 como en el tumulto de 1823. Finalmente, se marcan similitudes y/o contrastes en la tramitación de la disidencia política respecto de la primera década revolucionaria y se proyectan interpretaciones hacia adelante.

\section{La Sala de Representantes frente al conspirador Gregorio Tagle}

El descubrimiento de la conspiración de 1822 impactó de forma notoria en la agenda de discusión de la Sala de Representantes. Durante varias y prolongadas sesiones, los diputados se enfrascaron en acalorados debates que tocaron materias espinosas: la competencia de las autoridades para juzgar el asunto, la conveniencia de la implementación del juicio por jurados, la validez del otorgamiento de poderes excepcionales y la legalidad de la suspensión de los derechos individuales.

$\mathrm{Al}$ momento de reportar la conjuración a la Legislatura, Rivadavia presentó el dilema de quién debía arrogarse la facultad de enjuiciar al principal acusado, Tagle: "El gobierno ha considerado este un crimen de lesa patria que no está en sus atribuciones el juzgar por sí, ni por los tribunales ordinarios, sino que este juicio corresponde á la Sala de Representantes, constituida en un jury, ó en un tribunal de seguridad pública”. ${ }^{5}$ Las palabras del ministro de Gobierno, portavoz del gobernador, ponían de manifiesto la centralidad alcanzada por el legislativo durante el período de la "feliz experiencia", ya que el ejecutivo no solo decidió plantear el asunto en el recinto sino también recomendar que se hiciese cargo de juzgar el mismo (Ternavasio, 2004). Al mismo tiempo, sugirió los mecanismos judiciales más adecuados para proceder con Tagle: tribunales especiales y juicio por jurados. 
Los tribunales especiales fueron una práctica habitual durante los años revolucionarios para el juzgamiento de cierta clase de delitos o de personas específicas. Su creación se asentó en la retórica de la necesidad de hacer frente a circunstancias de excepcionalidad o delitos especialmente graves. El Tribunal de Seguridad Pública de 1811, la Comisión de Residencia de 1813 y la Comisión Civil de 1815 se formaron para enjuiciar a disidentes políticos, o bien, para sumariar a delincuentes en momentos críticos. Sin duda, la designación de jueces y el establecimiento de competencias respondían a una lógica circunstancial que pretendía una rápida resolución de casos considerados de extrema gravedad (Candioti, 2017). Por otro lado, la institución del juicio por jurados había ganado presencia en los debates suscitados en torno a la reforma judicial. Aunque solo se emplearon en los juicios de imprenta, existían opiniones ampliamente favorables respecto de la instauración de una justicia lega con participación ciudadana. Quiénes debían impartir justicia y con qué clase de magistrados se garantizaría rigurosamente el principio de igualdad ante la ley estaba en la base de la disyuntiva entre justicia letrada y justicia lega. No obstante, esa disyuntiva era más bien concebida como el planteo de alternativas complementarias para la administración de justicia. Los jurados no impugnaban la prerrogativa de la ley (que determinaba la definición de los delitos y regulaba la imposición de los castigos, ni la pericia del juez letrado (que aplicaba la ley), sino que con ellos se aspiraba a "democratizar" las resoluciones respecto de las condiciones de ejecución o no de un delito (Barreneche 2006; Candioti, 2008).

La Legislatura se encaminó hacia la alternativa del juicio por jurados. Una comisión especial ${ }^{6}$ presentó un proyecto de decreto para juzgar a Tagle, acusado de "crímen de conspiracion contra el órden, y seguridad pública”. El proyecto de treinta y seis artículos (impreso y repartido entre los diputados) establecía una junta de trece miembros, deducida "á la suerte" y presidida por un letrado. A cada representante le correspondía nombrar en sesión pública a un ciudadano (propietario, mayor de veinticinco años de años, sin dependencia del gobierno y de la representación de la provincia). La lista de posibles jueces sería entregada al fiscal y al acusado para que tuviesen oportunidad de impugnar hasta siete nombramientos. El día del juicio (que se desarrollaría de manera pública y sin interrupciones hasta su resolución), el presidente debía sortear a los jurados no recusados. Los que resultasen escogidos al azar estaban obligados a asumir la función, bajo amenaza de pagar una multa de quinientos pesos. A los juramentos de rigor -debían seguir- la lectura del acta de acusación, la presentación y el interrogatorio de los testigos de las dos partes y la contestación de los cargos por parte del imputado. Luego los jurados deliberarían en una habitación separada para resolver la cuestión, por mayoría de sufragios, en los siguientes términos: "Es culpable de tal delito, ó no es culpable". Si el fallo consideraba "no culpable" al acusado debía ser absuelto y puesto en libertad, mientras que si lo encontraba "culpable", el presidente del jurado determinaba la pena según la ley, daba aviso al gobierno y ordenaba la restitución del reo a prisión. ${ }^{7}$

El proyecto no llegó a ser tratado por la Sala porque la causa se topó con un escollo que parecía infranqueable: Celestino Vidal, que había delatado la conspiración, se negaba a declarar frente a un tribunal lo que de manera voluntaria había relatado frente al gobernador y tres de sus ministros. El cambio de actitud le valió al oficial ser suspendido como jefe al mando del regimiento de Cazadores y juzgado militarmente por perjurio. Pero lo más engorroso era que dicha "retratación" cerraba "las puertas á un inquirimiento legal" debiendo suspenderse el eventual proceso. Rivadavia observó que la situación de Tagle seguía siendo un asunto a resolver por parte de los diputados, porque "cargando el gobierno con sus deberes, debia la junta cargar con los suyos". El ministro de Gobierno enfatizó que tenían que dictaminar "con la independencia que les daba su caracter, y la que habia entre la representacion y el gobierno, entre quienes no se daba sino un punto de contacto, el interes del pais". ${ }^{8}$ Las nociones de cooperación y separación entre poderes sobrevolaban la prédica de Rivadavia (Ternavasio, 2004). El nuevo dictamen de la comisión especial fue leído en la sesión del 29 de agosto:

Un poder sujeto á formas y reglas judiciales no encontrará por donde dar principio á este juicio [contra Tagle]. En este estado, sí es preciso hacer algo, si la seguridad y la tranquilidad pública demandan en las actuales circunstancias alguna medida, es 
indispensable que ella sea obra de un poder púramente discrecional, sin sujeción á otra regla que su juicio privado (...) él es uno de los acciomas elementales sobre que reposa la tranquilidad de los estados.

El fragmento entrelaza varias cuestiones. En primer lugar, la apelación a la "tranquilidad pública" como recurso para reprimir a quienes eran considerados disidentes. Dicho principio (al que también se aludía como "orden público" o "seguridad pública") implicaba una suerte de convocatoria a respetar y mantener la unidad del cuerpo político. Los motines y las conspiraciones, en tanto ataques que perturbaban la armonía y provocaban divisiones en la comunidad, eran percibidos como crímenes de suma gravedad que ameritaban ser gestionados de manera expeditiva y excepcional (Godicheau, 2020). En relación a esto, la dimensión extraordinaria de las circunstancias aparecía como argumento normativo para canalizar jurídicamente parte de las nuevas tensiones políticas. Esta lógica del viejo orden jurídico mantuvo su vigencia, y ofrecía justificación institucional a la propuesta de la comisión, que podía ser cuestionada por hallarse en el límite entre el poder y la fuerza: la concesión de poderes de emergencia (Agüero, 2013).

La cuestión de los poderes de excepción o facultades extraordinarias fue habitualmente discutida luego de la revolución y en diferentes contextos para hacer frente a la conflictividad política, la fragmentación territorial y la guerra (Cansanello, 2003; Chiaramonte, 2010; Agüero, 2016). El otorgamiento al ejecutivo de dichas atribuciones se justificó en buena medida a partir de la "antigua constitución" (un conjunto de doctrinas provenientes del derecho natural y de gentes) que no solo proveyó a los actores pautas legitimadoras, sino también un legado institucional al cual echar mano para emprender la construcción de las nuevas entidades soberanas (Chiaramonte, 2010). Sobre este punto y ante el interrogante de si sería "prudente ó político delegar al gobierno ese poder discrecional" para que actuase "sin sujeción á ley, y por consiguiente sin responsabilidad", la comisión razonó que sería "terrible” colocar “en manos del poder ejecutivo una arma tan poderosa” puesto que ese "solo paso iba á minar, y destruir la nueva organización social”. La consideración del ejecutivo como un poder que "inspiraba zelos en el pueblo" y que "naturalmente se inclinaba á traspasar las leyes" abonaba el temor instalado durante los años siguientes a la revolución de que su refuerzo podía derivar en el despotismo de uno (Ternavasio, 2017). En contraposición a las prevenciones expresadas frente a un ejecutivo fortalecido, el informe aseguraba que "no se corrian grandes riesgos" en caso de conferir un "poder discrecional" al legislativo "porque nunca podia suponerse en los representantes del pueblo un deseo de abusar del poder, y mucho menos en aquellos en quienes el origen de su nombramiento era independiente, y presentaban al ciudadano la mejor garantia por la publicidad con que obraban". ${ }^{9}$ De esta manera, la tiranía de la mayoría era presentada como un peligro factible de ser conjurado básicamente por dos condiciones: los representantes se hallaban sujetos al control de la voluntad popular por medio del sufragio y a partir de la pública deliberación en las sesiones.

Agüero reforzó el dictamen comunicado por Rivadavia argumentación que "todos los estados" estarían "espuestos á disolverse" si por "un respeto ciego á los derechos del hombre" no se pusiese en ejercicio un poder de excepción "bajo la razon, la justicia, y el buen sentido." El representante desplegaba de este modo otro aspecto dilemático: la tensión entre tranquilidad pública y seguridad individual. Para ilustrar esta tensión evocó el caso de la "nación inglesa" que había suspendido "indefinida é indeterminadamente (...) la mayor y primera de sus leyes, la famosa de Habeas corpus" cuando vio "comprometida la seguridad pública”. Sin embargo, y a pesar de tomar como ejemplo a "la [nación] mas libre que conocia la europa", Agüero destacó que suspender de manera ilimitada aquella ley que resguardaba la "seguridad de las personas" no era la posición de la comisión que integraba, sino “adoptar medidas con respecto á una ú otra persona”, en este caso, Tagle. ${ }^{10}$

En el debate que se desarrolló para decidir la aprobación o el rechazo del dictamen se esbozaron tres posturas críticas. La primera, defendida principalmente por el diputado Gallardo, cuestionó a la comisión haciendo hincapié en que su resolución había faltado a la dinámica de funcionamiento del legislativo: debía determinar las medidas a adoptar "en un caso tan singular y extraordinario" y no dejar librada la tarea al "arbitrio" de los representantes, porque para eso se había "establecido el mecanismo de las 
comisiones". ${ }^{11}$ La segunda posición fue enarbolada por Paso, que también objetó la resolución de la comisión por ser insuficiente para "evitar la revolución” (de cuya veracidad estaba convencido) y aconsejó que el asunto quedara en manos de la policía para formar proceso informativo. ${ }^{12}$ Por último, Gazcón analizó la inconveniencia de que la Sala asumiera un poder discrecional para juzgar a un individuo en particular porque en la práctica era "imposible" y quimérico" como "librarlo al poder ejecutivo", por lo que lo más acertado era recurrir a dicho poder solo en providencias o medidas generales. ${ }^{13}$

El dictamen no fue aceptado y la Sala decretó el destierro de Tagle a un punto conveniente hasta que se resolviera su situación. No obstante, la medida no fue ejecutada y Tagle permaneció detenido en la ciudad, incomunicado y con la causa en su contra suspendida. Su esposa, Máxima Olmos, protestó sobre la situación en un extenso escrito:

\footnotetext{
"despues de desmentida la delacion por el mismo jefe que la dió, ya no hay materia para un juicio, porque no la hay para formar acusacion contra Tagle: esto mismo se ha sentado en la sala por los señores representantes, y desde este momento, se ha dicho que él es inocente ante la ley; pero si inocente ęcomo se le priva aun la menor de las libertades, de la comunicarse con su esposa y sus domésticos? ¿Que poder hay en el gobierno ni en la sociedad para aherrojarlo en una incomunicación que no iguala á la que sufriria el mas clasificado criminal? (...) Nuestros reglamentos patrios previenen que luego que al reo se le tome su confesion sea puesto en comunicacion, los mas alevosos asesinos gozan de esta disposicion humana. ¿Y por que Tagle no la disfruta cuando se confiesa que ni hay materia para acusarlo?"14
}

La representación de Tagle se montó esencialmente sobre las premisas de que la seguridad individual debía ser preservada por el gobierno y que la legislación debía ser respetada a fin de evitar el tratamiento arbitrario de quienes atravesaban (o no) un proceso judicial. La referencia concreta al decreto de seguridad individual, sancionado por el Triunvirato el 23 de noviembre de 1811, y la enumeración de sus transgresiones (en este caso, el menosprecio ante el principio de inocencia, el mantenimiento de la incomunicación, la prolongación del arresto y posteriormente, la imposición de destierro sin mediar una sentencia legal asentada sobre pruebas o indicios irrefutables del delito cometido) eran indicativas del empleo, cada vez más frecuente, de un lenguaje de los derechos (Candioti, 2017).

La Junta de Representantes se hizo eco de la reclamación y a principios de octubre de 1823, un mes después del primer decreto, ordenó que se levantara la incomunicación de Tagle y que saliese de la ciudad.

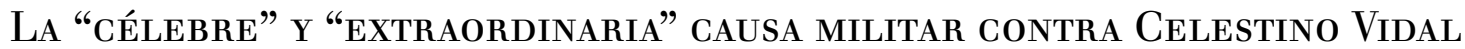

Celestino Vidal había sido quien delató a Tagle como el autor de la proyectada conspiración contra las autoridades provinciales. Pero al momento de comparecer frente a la justicia, en lugar de convalidar su denuncia, la desmintió. En el apartado anterior se han abordado las implicancias que dicha retractación tuvo en la suspensión del procesamiento del principal acusado. En el caso de Vidal, le valió ser imputado por el delito de perjurio en una causa abierta en la jurisdicción militar a comienzos de septiembre de $1822 .{ }^{15}$ La etapa de instrucción, destinada a recabar pruebas y testimonios para averiguar las condiciones de la comisión del delito, fue cumplimentada en poco más de una semana por el juez fiscal Benito Martínez, coronel del regimiento $\mathrm{n}^{\circ} 1$. Luego un consejo de guerra de oficiales generales (integrado por el coronel mayor Matías Zapiola, en calidad de presidente, y los coroneles Cornelio Zelaya, Rafael Hortiguera, Blas Pico, Gregorio Aráoz de Lamadrid, Manuel Ramírez y Mariano Benito Rolón) se reunió para estudiar el sumario, la acusación fiscal y el alegato presentado por el coronel mayor Juan José Viamonte, defensor de Vidal. ${ }^{16}$

En el cónclave (que tuvo lugar en la sala principal de la casa del Tribunal de Comercio y carácter público puesto que había sido anunciado con carteles por toda la ciudad) el presidente Zapiola manifestó que era necesario el nombramiento de dos letrados porque "se ventilaban puntos eminentes del derecho". Se incorporaron entonces Juan José Paso y el camarista Tomás Valle para asesorar tanto al consejo como al representante Esteban Gazcón, designado para auditar el proceso judicial. Finalmente, los coroneles 
convocados resolvieron que no era de su "competencia el sentenciar en esta causa, por no ser militar, sino de los comunes el delito que la motivó, y que por tal era del privativo conocimiento de la capitanía general". ${ }^{17}$

El consejo de guerra entendió que el delito de perjurio en el que había incurrido Vidal se enmarcaba en los delitos comunes considerados por las ordenanzas carolinas susceptibles de ser juzgados por la capitanía general, asumida por el gobernador de la provincia. Pero el ejecutivo sostuvo que "que la gravedad del asunto", "la publicidad" y "la imparcialidad" con que debía manejarse un juicio tan "celebre en su concepto" ameritaban desconocer "la imperfeccion de la ley". Por lo tanto, y hasta que no se reformase el código militar, solicitaba que el caso de Vidal, así como cualquier otro de similar naturaleza, fuese tramitado en un consejo de guerra. ${ }^{18}$

El contrapunto entre el consejo de guerra y el gobierno provincial daba cuenta que, si bien la tradición jurídica militar hispánica mantenía su vigencia, comenzaba a ser objeto de revisiones críticas que buscaban adecuarla a los nuevos principios jurídicos instaurados con la revolución y superar aquellos defectos que atentaban contra su rigurosidad y celeridad. (Abásolo, 2002, pp. 245-246). Es preciso recordar que el sumario sustanciado contra Vidal se dio mientras se encontraba en marcha un programa de reformas, que proyectaba modificar el carácter del fuero militar y encarar una codificación del régimen penal castrense. Medidas tales como la reducción del goce del fuero de los milicianos a su exclusiva persona, la supresión de la jurisdicción de los tribunales castrenses en asuntos de naturaleza mercantil y, especialmente, la definitiva abolición del carácter personal del fuero castrense a mediados de 1823 formaron parte de dicho proceso (Abasolo, 2002, pp. 229-235).

La Sala de Representantes derivó a la comisión de milicia la providencia del consejo de oficiales, la proposición del ejecutivo y una representación del defensor de Vidal en la que solicitaba "el puntual cumplimiento de la ordenanza, sin que se hiciese lugar a inovacion alguna". ${ }^{19}$ En su informe, la comisión resaltó que el "pueblo" estaba "acostumbrado notablemente á ver, y oir" a sus "representantes" en "discusiones y pronunciamientos definitivos en los negocios de la mayor gravedad é intereses" por lo que no les resultaban "indiferentes los juzgamientos privados, ó aislados en el estudio ó bufete de un juez". Para alejar "toda sospecha" de la "conducta" e "integridad de los juzgadores", el proceso judicial de Vidal había sido anunciado públicamente. El "pueblo espectador" había asistido ya a la "acusacion y defenza del reo” y solo le restaba "enterarse de la discusion, pronunciamietno de los vocales, y sentencia". Como el asunto se encontraba entonces "en un punto de vista arto difícil para arrivar á una final determinación" que no defraudara "la justicia de la parte, ni la de la seguridad publica, amenazada de una conjuracion”, la comisión propuso que la Sala de Representantes sancionase que las causas de igual naturaleza a la de Vidal fuesen juzgadas en consejo de guerra hasta tanto no se reformara el código militar. ${ }^{20}$

A la lectura del dictamen siguió el debate en la Legislatura. Gazcón, el asesor del gobierno en la causa, analizó las dos alternativas barajadas para juzgar al oficial imputado. La primera, que consistía en la proposición del ejecutivo de nombrar un consejo de guerra, no era conveniente en su opinión porque suponía introducir una "novedad de trascendencia e injusticia" que trastornaría "las leyes de la sociedad" y frustraría "uno de los códigos mas preciosos, que habia merecido los elogios de las naciones". Gazcón recalcó que "juzgar á un reo por una nueva ley formada" especialmente para el caso era "lo mas temible, lo mas impolítico, lo mas injusto, y lo mas irracional" porque "no podía haber hombre seguro, siempre que las leyes no tubiesen toda estabilidad que era indispensable”. Por lo tanto, Gazcón adhirió a la segunda alternativa por la cual la Sala debía nombrar un oficial de graduación competente que en clase de capitán general sentenciase con dictamen de un auditor particular. Dicho nombramiento, pretendía ser una salida al atolladero que planteaba el hecho de que "el gobierno como capitán general no podía conocer en la causa porque aparecía en calidad de parte”. Además de discrepar con el gobierno en su diagnóstico sobre las leyes militares heredadas, el asesor optaba por tomar como bandera la defensa de las garantías individuales frente a la excepcionalidad de las circunstancias, de esta manera intentaba amalgamar una tradición jurídica de viejo cuño con principios y valores recientemente incorporados. 
El diputado García, integrante de la comisión militar, intervino para aclarar uno de los puntos del dictamen: aquel relativo a la calificación del delito perpetrado por Vidal. Ante la falta de discusión respecto de si el delito tenía o no conexión con el servicio, la comisión había estimado que la falta era en servicio y por eso debía ser juzgado en consejo de guerra nombrado por el capitán general, ya que no había "abdicado sus funciones". Esta opción era lo más propicio para Vidal porque además de no entrañar parcialidad alguna (según las ordenanzas era el capitán general "quien mandaba formar los consejos"), se ajustaba a lo resolución de la Junta de que el juzgamiento fuese "público para que "el pueblo se acostumbrase á esta clase de juicios". ${ }^{21}$

El dictamen de la comisión también fue reprobado por el representante Somellera, que planteó una tercera posición: Vidal debía ser enjuiciado por el inspector general para asegurar la imparcialidad. El letrado enumeró dos motivos en su alocución. El primero era que si bien las leyes militares carolinas especificaban que las faltas no conectadas con el servicio debían ser juzgadas por el capital general, durante los años precedentes había sido el jefe de armas quien sentenciaba en esas causas, luego revocadas o confirmadas por el director supremo:

"Que esta costumbre se elevó a ley porque el reglamento del congreso general disponia que el director supremo conociese en las apelaciones de las causas que antes iban al supremo consejo de guerra, que eran las que se formaban por delitos comunes y de que no debía conocerse en consejo de guerra con arreglo a la orden del 12 de marzo de 1781. (...) Que á la inspeccion era á quien correspondia conocer en la causa, porque habiendo cesado en el año 20 el estado mayor, se publicó después una orden, que corria en las gacetas, dando al inspector las mismas funciones que tenia el jefe del estado mayor dando al inspector las mismas funciones que tenía el estado mayor."22

Aunque luego de 1810 las viejas ordenanzas militares españolas mantuvieron su vigencia, con el uso muchas disposiciones carolinas fueron modificadas gradualmente, atendiendo a ciertas circunstancias, como por ejemplo, las urgencias de la guerra. De esta manera, el conocimiento de la práctica patria en materia de asuntos jurídico militares se volvió significativo (como puede observarse en la intervención de Somellera), debido a la escasa erudición que, sobre el derecho penal castrense, mostraba buena parte de los que debían impartir justicia en la jurisdicción militar. (Abásolo, 2002, pp. 245-261). Este fue justamente el segundo motivo recurrido para cuestionar la pertinencia del consejo de guerra: el "poco conocimiento" que los generales tenían en la legislación referida a los delitos comunes, advirtiéndose esta situación en la causa de Vidal porque había sido necesario el nombramiento de dos auditores para asesorarlos. ${ }^{23}$ Paso también criticó la opción del consejo de guerra, retomando en su exposición la disparidad existente al momento de evaluar delitos militares y delitos comunes que había planteado Somellera:

\footnotetext{
"Que el consejo de guerra, compuesto de oficiales generales, juzgaba por el código que el servia de regla; y juzgaba breve y sensillamente, por cuanto las leyes de la ordenenza eran breves y sencillas; los derechos alli no se sujetaban á discusiones prolijas, pues que siendo claras las penas y propias de los delitos, facilemnte inclinaban el ánimo de los jueces á decidir si estos estaban, ó no; comprendidos en aquellas. Pero cuando los delitos no eran del servicio, si no de los comunes, entonces se complicaban; y envolvian en dificultades, por que las leyes no eran claras ni tan sencillas [y para su aplicación] se necesitaba mayor discernimiento."
}

El proyecto de la comisión no fue aprobado por los diputados, que revolvieron en conclusión pasar la causa al inspector general para que sentenciara "según la práctica observada en casos de esa naturaleza". El inspector general sobreseyó a Vidal y dispuso su libertad y la restitución de su empleo. Pero semanas más tarde el oficial elevó una queja a la Junta porque a pesar de la sentencia continuaba en prisión. Al estudiar nuevamente su situación, Rivadavia declaró, como portavoz de la comisión de milicia, que la causa "estaba enredada y paralizada" porque el consejo de guerra se había declarado "incompetente” luego de diferenciar entre delitos comunes y militares, y porque el inspector general había emitido un "caprichoso fallo", evitando declarar culpable o inocente a Vidal. Por eso opinaba que el inspector debía revisar el sumario, dictar sentencia legalmente definitiva y notificar a la capitanía general. ${ }^{24}$ Paso repuso que el veredicto había procurado "conciliar (...) los respetos del gobierno" con "la inculpabilidad del coronel acusado", quien había preferido 
“cargarse con la corteza del delito por no aparecer delator". Y agregó que la inspección había informado al gobierno antes de liberar a Vidal porque la causa "tenia su emanacion de la sedición que se anunció, por consiguiente de trascendencia á la seguridad pública, de que el jefe supremo dela provincia era el principal encargado". ${ }^{25}$ La Sala rechazó la postura de la comisión y ordenó que el inspector efectivice la sentencia pronunciada.

\section{CONSPIRADORES, PATRICIDAS Y TUMULTUARIOS EN LA "FELIZ EXPERIENCIA"}

Una de las acusaciones que enfrentó Tagle a raíz del incidente de 1822 fue la de haber perpetrado el "crímen de conspiracion contra el órden, y seguridad pública". ${ }^{26}$ Algunos de los elementos que construyeron el delito y sus promotores se advierten en el siguiente fragmento del discurso del ministro Rivadavia:

\footnotetext{
"Que cuando el gobierno ponia en movimiento los resortes todos para hacer la felicidad del pais, cuando trabajaba en que se respetasen las personas, y las propiedades, cuando á nadie se incomunicaba, y se dispensaban consideraciones á los hombres, y cuando ya parecia que se tocaban los momentos de una prosperidad firme: entonces no osando presentarse en público se serpenteaba entre las cavernas, y se seducía al bajo pueblo para destruir el país (...) Que el gobierno estaba convencido que el mal de la insurreccion era el mal capital de este pais, porque habia una porcion de hombres, que han creido que los derechos de los pueblos son propiedades suyas, y que pueden disponer de este pueblo como de los salvages de la campaña; y sin que ese mal se curase de raiz, eran inutiles todos los sacrificios." ${ }^{27}$
}

El carácter oculto y encubierto de la conjura negaba toda legitimidad a la práctica política de resistencia emprendida por los disidentes. En este sentido, la figura delictiva fungía como "arma política” destinada no solo a impactar entre las filas del propio gobierno sino también a provocar el repudio de sectores más vastos de la población, y en consecuencia, su adhesión a las medidas represivas ensayadas (Mendoza Molsalvo \& Calderón, 2011). Esas medidas debían salvaguardar el orden público -amenazado por los "metodos de violencia" - que los "miembros de la administracion" se habían esforzado por reinstaurar luego de padecer durante la década precedente los efectos no deseados de la revolución. Un orden que, como se advierte en la cita, se desglosaba en varios niveles: jurídico, económico, político-institucional y social.

El evento conspirativo planificado por Tagle tenía el agravante de pretender "seducir" al pueblo para que atentara contra las autoridades constituidas, es decir, buscaba arrastrar a los habitantes al desacato. La aprensión mostrada ante la eventual movilización de sectores plebeyos, urbanos y rurales, se correspondía con el repertorio de disposiciones adoptadas durante esos años con el objetivo de restringir cualquier actuación política popular (Di Meglio, 2007, pp. 222-223).

Esas expresiones políticas consideradas ilegítimas, se inscribían además en la serie de "insurrecciones" y "revoluciones" que había caracterizado a la década revolucionaria. Regular la competencia por el poder para evitar que se vulneraran los canales "institucionales" no había resultado sencillo en un contexto de disputas en torno a los principios de legalidad y legitimidad, de superposición de prácticas e instituciones antiguas con pautas y mecanismos nuevos de organización política; en definitiva, en un contexto de provisionalidad permanente (Chiaramonte, 1997). Estos desbordes en la contienda política además de entorpecer la consolidación del nuevo orden, revelaban las nefastas consecuencias de las divisiones que atravesaban al grupo dirigente.

La imagen de que las disidencias al interior del cuerpo político comenzaban a ser superadas durante el período rivadaviano fue plasmada en las páginas de El Centinela en ocasión del fracaso del segundo movimiento liderado por Tagle en agosto de 1823. El periódico oficial rescataba la Ley de Olvido para mostrar cómo su sanción había representado el punto cúlmine de la recomposición de la unanimidad jaqueada por las "facciones" y los "partidos" 28 :

\footnotetext{
“¿No es verdad que desde entonces [la sociedad] dejó de presentar el triste aspecto de pequeñas porciones de hombres aislados, y enemigos unos de otros, tal vez sin saber por qué? ¿No es verdad que todos los partidos en que ha hervido la revolucion,
} 
se concentraron, se unieron, y marcharon de acuerdo con la autoridad, y en comun, por la senda, ántes desconocida, de la civilizacion, el honor, la moral? (...) No hai mas que echar una mirada rápida por nuestra sociedad en general, y sus miembros en particular: todos unidos, todos amigos, ya se han olvidado hasta los dictados con que eran marcados los pertenecientes á esta ú aquella faccion, y cuyos nombres derivaban del de aquel que la presidía.”

La Ley de Olvido, dictada en septiembre de 1821 por la Sala de Representantes, estableció que los procesos judiciales originados "por opiniones políticas" con anterioridad a su sanción no impedirían a ningún individuo "el pleno goze" de su "seguridad". La ley alcanzó a quienes habían sido juzgados y sentenciados por delitos políticos, pero también a los que habían sido desterrados sin una causa previa. En virtud de la resolución podían regresar a la provincia los comprendidos por la ley pero también aquellos que de manera voluntaria habían emigrado para "ponerse á cubierto de los riesgos de las agitaciones populares”. No serían beneficiados, sin embargo, los individuos que habían continuado propiciando "proyectos de conspiración contra el gobierno, y tranquilidad dé la provincia" y los oficiales que habían "desertado de sus banderas". La ley de olvido fue concebida por el gobierno provincial como un requerimiento necesario para alcanzar la reconciliación luego de diez años signados por luchas internas. La medida obraría como estrategia orientada a restablecer la unidad, pero ya no de todo el territorio rioplatense sino de la provincia de Buenos Aires, que buscaba con el plan de reformas impulsado por el gobierno dejar atrás los convulsos años precedentes para darse a la tarea de reconstruirse (Polastrelli, 2019, pp. 307-312).

Para El Centinela los amotinados de la noche del 19 de marzo de 1823 eran los "únicos" que no habían acordado "jamás ni con el órden ni con los principios" porque estaban "connaturalizados con los delitos mas horrendos". En definitiva, eran "los verdugos eternos de la Patria y los asesinos de su reputacion”, a cuya cabeza se encontraba Tagle:

“un hombre que puso á su Patria en pública subasta; que engrosó enormemente su tesoro particular á costa del del público; que se hizo un sistema del despotismo; que preparó la anarquía; que lanzó más allá de los mares centenares de inocentes; que por un golpe de autoridad asaltó el tálamo ageno; que hizo del espionaje una virtud; de la confianza doméstica un juego; y un desprecio continuado de la seguridad del ciudadano". 30

El repaso de la trayectoria política de Tagle venía a corroborar el talante de un hombre siempre propenso a delinquir y que no tenía reparos en recurrir a todo tipo de maniobras a fin de "destruir la representacion de la provincia y el gobierno", y en definitiva, de "conmover el pais" ${ }^{31}$ La peligrosidad de su conducta habilitaba en consecuencia la acusación lanzada por Rivadavia de haber incurrido en el "crimen de lesa patria". Dicho crimen remitía sin dudas al de "lesa majestad", caracterizado en las Leyes de Partidas como la traición contra la persona del rey o contra sus posesiones. ${ }^{32}$ Suponía no solo una desobediencia a la superioridad terrestre sino también a la celeste, ya que la ofensa al rey (en su persona, en su majestad y en su soberanía) significaba la transgresión a un orden que era indisponible e incuestionable. La torsión semántica de la acusación exhibe las mutaciones producidas en el orden político y, fundamentalmente, en el principio de legitimidad que lo sustentaba: el máximo valor que lesionaban quienes fueron acusados de cometer delitos políticos ya no era dios (como garante del orden sagrado e indisponible de las monarquías de Antiguo Régimen) sino la patria (Barriera, 2018).

Además de enfrentar los cargos de "quebrantamiento de cárcel” y de "soltura de presos", José María Urien debió responder a la acusación de "patricida" y "traidor". Urien se encontraba preso por haber asesinado al marido de su amante cuando estalló el movimiento de 1823. Escapó de la cárcel junto a otros prisioneros y se plegó a la "revolución". Apresado, el gobierno le ofreció una garantía para que confesara los pormenores del plan, pero luego le fue negado el beneficio por lo que concluido la causa judicial en su contra, fue condenado a muerte. ${ }^{33}$ El escrito presentado por el defensor de pobres, Ramón Díaz, para librar a Urien de la pena del último suplicio muestra algunos elementos más que dieron forma a los delitos de lesa patria y alta traición. Díaz argumentó que Urien no era "Patricida" puesto que no había "vendido á su Patria", no había pactado "con sus enemigos para hacerla perder su dependencia", ni había "desconocido la soberanía de 
su Pais, atacando (...) en sus fundamentos el orden social". Por lo tanto, no podía ser condenado tomando como referencia la ley de las Siete Partidas que establecía "la setena manera de ser traidor": "facer bollicio, ó levantamiento faciendo juras ó cofradías de Cavalleros contra el Rey, y el Reyno, ó sublevando villas contra el mismo." Para el letrado era imposible que su defendido pudiera reunir a cierto número de personas que atentaran "contra la tierra" porque no solo había estado prisionero en un calabozo por casi un año ("abandonado hasta de sus amigos"), sino también porque no había logrado encontrar un padrino para el momento de su confesión. ${ }^{34}$ En cambio, la ley por la que debía ser juzgado Urien era la "Ley Patria" del 26 de septiembre de 1820. El decreto sancionado en esa fecha por la Junta de Representantes definió quienes en adelante serían considerados "enemigos":

\footnotetext{
"Fin a las alteraciones, y á la amargura, principio al orden, reconocimiento, obediencia, y respeto a la autoridad representativa y primera de la Prov.a, y á sus determinaciones. Los q.e promovieren la insurreccion, perturbaren la tranquilidad publica, ó atentaren contra esta autoridad, y las demas constituidas, o q.e se constituyeren en la Prov.a, los q.e de igual modo promovieren, u obrasen la discordia entre los Pueblos de la misma, los q.e auxiliaren, o dieren cooperación ó favor directa, óindirentam.te, seran reputados enemigos de la Prov.a y perturbadores del orden y tranquilidad publica, y castigados con todo el rigor de las penas, hasta la de muerte y expatriación, conforme a la gravedad del crimen, y parte de accion, o influxoq.e tomaren. No hay clase, ni persona residente en el territorio de la Prov.a exenta de la observancia, y comprensión de este Decreto, ninguna causa podra excusar su infraccion." 35
}

Del repertorio de normativas disponibles, el defensor optó de manera estratégica por aquella que permitiría aminorar el castigo aplicado a Urien. A criterio de Díaz, la "Ley Patria” clasificaba al movimiento del 19 de marzo de 1823 como "perturbacion del orden publico con ataque delas autoridades" y dejaba al arbitrio del juez la imposición de las penas según los grados de acción de los participantes. La cuestión era entonces dilucidar, según la escala que designaba la ley, si la intervención de Urien merecía la pena mayor. Para eso el defensor recorrió los hechos que sostuvieron las acusaciones. En primer lugar, señaló que su apoyo al movimiento se debió a que los "conjurados" le habían asegurado que "una gran parte de la poblacion se pondria en armas contra la autoridad", que sería puesto en libertad y se le haría jefe de doscientos hombres", y finalmente, "que su resistencia a cooperar no haría más que sumergirlo en peores males". Además, no podía compararse la exposición de Urien en el lugar de los incidentes con la de aquel que "en el sosiego de su casa" había delineado todos los pormenores de "un plan subversivo". Si a este último, le correspondía la pena de muerte por ser "el motor primero de la sedición", era improcedente que alguien cuya "parte de acción" era subalterna en sumo grado" fuese condenado de la misma forma. En segundo lugar, desmintió que Urien amotinara y liberara a los presos de la cárcel, indicó que en realidad había puesto en riesgo su vida al imponerles "respeto" y evitar "un atropellamiento que hubiera sido funesto". Por último, frente al cargo de haber obrado con los "conjurados contra las fuerzas de la autoridad”, Díaz replicó que "concurrir al choque lejos de aumentar la criminalidad de Urien" lo diferenciaba de aquel que "con verdadera alevosia sin exponer su cuerpo á los peligros" había hostilizado a las autoridades "vilmente desde un punto escondido". Por todo lo expuesto, el defensor de pobres solicitó al juez la "pena intermedia" que su "arbitrio prudente" considerara conveniente. ${ }^{36}$

A pesar de los argumentos del letrado, y como ya se mencionó, Urien fue condenado a muerte por el juez comisionado Juan García de Cossio. Otra fue la suerte de tres individuos apresados por tañer la campana del cabildo. José María Palacios, Fermín Viera y Benito Rubio fueron catalogados como "traidores" y "rebeldes" por haber concurrido con "los facciosos anarquistas", cooperado tocando la campana "de la ciudad" para “aumentar el tumulto" y "propagar el desorden”. El magistrado de primera instancia Bartolomé Cueto, luego de tomarles breves declaraciones, los sentenció a la pena de horca por haber "atentado contra las autoridades constituidas". Pero el expediente fue revisado por el Superior Tribunal de Justicia que, citando a la Pragmática de Asonadas, consideró que la sustanciación del juicio, adolecía de faltas notorias que perjudicaban la situación procesal de los imputados, como por ejemplo, no haber nombrado padrinos, no tener oportunidad para presentar sus defensas y no ser citados para comunicarles la sentencia. Los camaristas devolvieron el juicio 
y exigieron al juez que subsanara los errores, quien terminó considerando que los procesados eran "hombres de condicion humilde, escasos de discernimiento y luces, y sin representacion" y que por eso era pertinente "modificar el rigor de la pena”. Así, Cueto les impuso custro años de destierro en la isla Martín García para que "con su travajo personal sirvan a a la Ptria ofendida, y expíen su delito". ${ }^{37}$

\section{CONSIDERACIONES FINALES}

La apelación a la justicia para resolver las disputas políticas entre los miembros de la dirigencia política fue un rasgo característico de la revolución rioplatense durante la década de 1810. Las sucesivas autoridades de Buenos Aires recurrieron asiduamente a los procesamientos judiciales para condenar a quienes fueron considerados disidentes. Así, partícipes de conspiraciones, tumultos y sublevaciones que cuestionaron al poder central, jefes militares y políticos que provocaron suspicacia en los gobiernos al estar su adhesión puesta en entredicho y gobernantes destituidos y acusados de delitos políticos desfilaron frente a diversos tribunales y comisiones. La implementación de un gran repertorio de mecanismos judiciales y de lógicas jurídicas para reprimir y castigar a los disidentes durante la primera década revolucionaria (la designación de jueces comisionados, el otorgamiento de facultades extraordinarias, la creación de tribunales de seguridad pública, los juicios de residencia, la suspensión de garantías individuales, la imposición de condenas sumarias, el solapamiento de justicia ordinaria y justicia militar) respondió a un uso estratégico que pretendió dar solución a situaciones conflictivas consideradas una amenaza para la estabilidad del orden vigente (Polastrelli, 2019).

¿Qué es lo que ocurrió entonces con la tramitación de la disidencia política luego de la crisis de 1820 ? El gobierno ahora provincial se empeñó en judicializar los dos episodios referidos a lo largo de las páginas precedentes. Luego de ser descubierta la primera conspiración antes de que pudiera concretarse (a raíz de la delación del oficial Celestino Vidal), la Sala de Representantes se enfrascó en espinosas discusiones para determinar la competencia de las autoridades para juzgar al principal acusado, la conveniencia de implementar el juicio por jurados, la validez del otorgamiento de poderes excepcionales y la legalidad de la suspensión de garantías individuales. La sofisticación de los debates desarrollados durante las sesiones daba cuenta de la preocupación por cubrir jurídica y judicialmente la criminalización de la disidencia política, aunque el modo no estaba del todo claro. Es más, la indefinición respecto de a qué prácticas judiciales y lógicas jurídicas era adecuado recurrir derivó en la imposibilidad de formalizar el procesamiento de Tagle.

Aunque también malogrado, el segundo incidente (catalogado frecuentemente como "motín", "asonada" o "tumulto") evidenció la existencia de conflictos que en más de un caso se debían a la oposición al avance de las reformas, más allá del optimismo que embargaba a la dirigencia provincial. Marcó, asimismo, un retorno a las formas de participación de la década anterior, con dos elementos novedosos: la abierta aparición de la religión en la escena política y la intervención de gente de la campaña (Di Meglio, 2007; Lida, 2009). $\mathrm{Al}$ igual que en la desarticulada conspiración del año anterior, Tagle logró librarse de comparecer ante un tribunal (aunque esta vez debido a su fuga) pero muchos de los involucrados no tuvieron la misma fortuna y debieron afrontar causas judiciales. Setenta partícipes del tumulto fueron procesados en veintitrés sumarios, que se tramitaron de manera expeditiva. Unos pocos días bastaron para que los jueces dictaran las sentencias: absolución, libertad bajo fianza, destierro, presidio y pena de muerte en tres casos (además de José María Urién, fueron fusilados Juan García y Benito Peralta).

Luego del fracaso de las conjuras de Tagle, la actividad política se reencauzó en buena medida hacia la competencia mediante el sufragio. El acuerdo tácito que posibilitó la aparente suspensión de las disputas facciosas entre los grupos de la elite bonaerense se resquebrajó durante la reunión del Congreso Constituyente de 1824-1827 (Ternavasio, 1999; 2018). La confrontación dentro y fuera de la provincia no tardó en aparecer, ahora con motivo del proceso de unificación nacional que buscó nuevamente capitanear Buenos Aires. En un contexto de precariedad institucional y de fuerte descontento producto de la guerra con 
el Brasil, el dramático fusilamiento del gobernador Manuel Dorrego en 1828 acabó de manera brutal con la tregua e inició a un período dominado por una nueva lógica de violencia y faccionalismo extremos. Era la primera vez desde la independencia que un gobernador en funciones era pasado por las armas, quebrando la “tradición amable" de la política revolucionaria porteña (Halperin Donghi, 2005). ${ }^{38}$

Las formas que adoptó la tramitación de las disidencias políticas exhibidas en los movimientos que buscaron destituir a los gobiernos de turno revelan, en conclusión, los diferentes momentos que experimentó la década de 1820. Mientras que las conspiraciones tramadas por Tagle funcionaron como un epílogo de la década revolucionaria -en tanto corolario de la supresión del cabildo, práctica política ligada al asambleísmo y conflicto judicializado- la sublevación de Lavalle, el fusilamiento de Dorrego y la redefinición de las disputas por el poder en términos de antagonismo faccioso, operaron como un prólogo del nuevo período abierto con la llegada de Rosas a la gobernación de Buenos Aires.

\section{REFERENCIAS}

Abásolo, E. (2002) El derecho penal militar en la historia argentina. Córdoba: Academia Nacional de Derecho i Ciencias Sociales de Córdoda.

Agüero, A. (2013) La Asamblea del año XIII y la dimensión extraordinaria del orden jurídico tradicional. Reflexiones en torno al juramento e instrucciones del cabildo de Córdoba. Anuario del Instituto de Historia Argentina, 13, $1-27$.

Agüero, A. (2016) Ancient Constitution or paternal government? Extraordinary powers as legal response to political violence (Río de la Plata, 1810-1860). Max Planck Institute for European Legal History Research Paper Series, $10,1-31$.

Barreneche, O. (2006) ¿Lega o letrada?. Discusiones sobre la participación ciudadana en la justicia de la ciudad de Buenos Aires durante las primeras décadas de independencia y experiencia republicana. En Palacio J. M. \& Candioti M. Justicia, Politica y Derechos en América Latina (pp. 181-202). Buenos Aires: Prometeo.

Barriera, D. (2018) La historia del poder político rioplatense durante el "periodo colonial": interpelaciones desde el prisma de la historia de la Justicia. En Peire J., Amadori A. \& Chaile T. Historiografias político culturales rioplatenses. Itinerarios, enfoques y perspectivas (pp. 23-56) Sevilla: Thémata

Candioti, M. (2008) Fueros, jueces y jurados: el debate público en torno a la reforma judicial rivadaviana. Papeles de Trabajo. Revista Electrónica del IDAES, 1-19.

Candioti, M. (2017a) “Una época en la que Ciudadano ve su seguridad individual respetada”. La circulación del lenguaje de los derechos en los tribunales de la Buenos Aires posrevolucionaria (1810-1830). Secuencia. Revista de Historia y Ciencias Sociales, 98, 35-65.

Candioti, M. (2017b) Un maldito derecho. Leyes, jueces y revolución en la Buenos Aires republicana, 1810-1830. Buenos Aires: Didot.

Cansanello, O. C. (2003) De súbditos a ciudadanos. Ensayo sobre las libertades en los orígenes republicanos. Buenos Aires 1810-1852. Buenos Aires: Imago Mundi.

Castro, F. \& y Terrazas, M. (2003) Disidencia y disidentes en la historia de México. México: Universidad Nacional Autónoma de México.

Chiaramonte, J. C. (1997) Ciudades, provincias, estados: Origenes de la Nación Argentina (1800-1846), Buenos Aires: Ariel.

Chiaramonte, J. C. (2010) La antigua constitución luego de las independencias, 1808-1852. Desarrollo Económico, 50(199), 331-361.

Di Meglio, G. (2007) „Viva el bajo pueblo! La plebe urbana de Buenos Aires y la politica entre la Revolución de Mayo y el Rosismo. Buenos Aires: Prometeo.

Di Meglio, G. (2014) Manuel Dorrego. Vida y muerte de un líder federal. Buenos Aires: Edhasa. 
Fradkin, R. (2008) ¡Fusilaron a Dorrego! o cómo un alzamiento rural cambió el rumbo de la historia. Buenos Aires: Editorial Sudamericana.

Godicheau F. (2020) El orden público constitucionalizado: principio de unidad y arma contra enemigos interiores. En Lorente Sariñena M., ; Garriga Acosta C., Portillo Valdés J. M. \& ; Vallejo J. Historia constitucional de la monarquia española (1700-1823), 2, in Press. Recuperado de: https://halshs.archives-ouvertes.fr/halshs-02527 486

Guerra, F. G. (1994) La metamorfosis de la representación en el siglo XIX. En Couffinal G. (Comp.) Democracias posibles: el desafio Latinoamericano (39-68). México: Fondo de Cultura Económica.

Halperin Donghi, T. (2005) Revolución y guerra. Formación de una elite dirigente en la Argentina criolla. Buenos Aires: Siglo XXI Editores Argentina.

Herrero, F. (2018) Voces de invasión e iniciativas disruptivas en Buenos Aires en los primeros años de la década de 1820. Claves. Revista de Historia, 4, 6, 95-124.

Lida, M. (2009) La cuestión religiosa y la cultura política revolucionaria en la ciudad de Buenos Aires a comienzos del siglo XIX. En Bragoni B. \& Mata S. Entre la Colonia y la Revolución, Insurgencias, rebeliones y cultura politica en América del Sur (pp. 269-292). Buenos Aires: Prometeo.

Mendoza Monsalvo, E. \& Conde Calderón, J. (2011) La conspiración como arma política. El plan sedicioso del 14 de agosto de 1833 en Cartagena. Revista Complutense de Historia de América 37, 73-92.

Piccirilli, R (1948) Las reformas económica-financiera, cultural, militar y eclesiástica del gobierno de Martín Rodríguez y el ministro Rivadavia. En Levene, R. Historia de la nación argentina (pp. 275-376). Buenos Aires: El Ateneo, vol. VI.

Polastrelli, I. (2019) Castigar la disidencia. Juicios y condenas en la elite dirigente rioplatense, 1806/08-1820. Buenos Aires: Academia Nacional de la Historia.

Rosanvallon, P. (2007) El modelo politico francés. La sociedad civil contra el jacobinismo, de 1789 hasta nuestros dias. Buenos Aires: Siglo XXI.

Sbriccoli, M. (1973) Dissenso politico e diritto penales in Italia tra Otto e novecento. Il problema dei reati politici dal Programma di Carrara al Trattato di Manzini. Quaderni fiorentini per la storia del pensiero giuridico moderno, 2, 607-702

Sbriccoli, M. (1974) Crimen lease maiestatis. Il problema del reato politico alle soglie della scienza penalistica moderna. Milán: Giuffrè.

Ternavasio, M. (1999) Las reformas rivadavianas en Buenos Aires y el Congreso General Constituyente (1820-1827). En Nueva Historia Argentina (pp.159-199). Buenos Aires: Editorial Sudamericana, t. 3.

Ternavasio, M. (2004) Construir poder y dividir poderes. Buenos Aires durante la feliz experiencia rivadaviana. Boletín del Instituto de Historia Argentina y Americana "Dr. Emilio Ravignani”, 26, 2004, 7-43.

Ternavasio, M. (2017) La fortaleza del Poder Ejecutivo en debate: una reflexión sobre el siglo XIX argentino. Revista Historia, 24 (2), 5-41.

Ternavasio, M. (2018) Prelude to dictatorship: the elections of 1827, 1828, and 1829 in Buenos Aires. En Robertson A. \& Posada-Carbó E.(Comps). The Oxford Handbook of Revolutionaty Elections in the Americas, 1800-1910. Oxford: Oxford University Press.

\section{Notas}

1 Sobre el concepto de disidencia véase (Sbriccoli, 1973; Castro \& Terrazas, 2003).

2 Un relato pormenorizado de los episodios se encuentra en (Piccirilli, 1948). Las motivaciones de la participación plebeya en el motín fueron abordadas en (Di Meglio, 2007). Sobre el carácter rupturista de las llamadas "conspiraciones de Tagle" véase asimismo (Herrero, 2018).

3 Diario de Sesiones de la H. Junta de Representantes de la Provincia de Buenos Aires, 1822, vol. VII, p. 152.

4 El Argos de Buenos Aires, 22 de marzo de 1823. Citado en (Piccirilli, 1948, p. 366).

5 Diario de Sesiones de la H. Junta de Representantes de la Provincia de Buenos Aires, 1822, vol. VII, p. 153. 
6 El presidente de la Sala de Representantes designó a Julián Segundo de Agüero, Valentín Gómez, Alejo Castex, Pedro Alcántara de Somellera y a Bernardino Rivadavia para integrar dicha comisión.

7 Proyecto de decreto. Honorable Sala de Representantes de la Provincia, Buenos Aires, 1822. Recuperado de: https://arch ive.org/details/proyectodedecret00buen

8 Diario de Sesiones de la H. Junta de Representantes de la Provincia de Buenos Aires, 1822, vol. VII, p. 169.

9 Diario de Sesiones de la H. Junta de Representantes de la Provincia de Buenos Aires, 1822, vol. VII, p.180.

10 Diario de Sesiones de la H. Junta de Representantes de la Provincia de Buenos Aires, 1822, vol. VII, p.179.

11 Diario de Sesiones de la H. Junta de Representantes de la Provincia de Buenos Aires, 1822, vol. VII, p. 181.

12 Diario de Sesiones de la H. Junta de Representantes de la Provincia de Buenos Aires, 1822, vol. VII, p. 183.

13 Diario de Sesiones de la H. Junta de Representantes de la Provincia de Buenos Aires, 1822, vol. VII, p. 187.

14 H. J. de Representantes. : Doña Máxima Olmos, muger legítima del Dr. D. Gregorio Tagle, prestando por él, voz y caucion, implora de la autoridad que reviste V. H. y delpoder discrecional que se ha puesto en ejercicio contra su persona, 1822, Buenos Aires, Imprenta de alvarez. Recuperado de: https://archive.org/details/hjderepresentant00olmo/page/n1/mode/2up

15 Las diligencias iniciales fueron detalladamente reproducidas en el periódico El Centinela, no 8, 15 de septiembre de 1822.

16 Los tribunales colegiados destinados a impartir justicia militar eran de dos tipos: los consejos de guerra ordinarios (que juzgaban a las clases y a los soldados) y los consejos de guerra para oficiales generales. En ambos casos, se formaban especialmente para la ocasión con oficiales de las distintas armas (Abasolo, 2002, p. 64).

17 Diario de Sesiones de la H. Junta de Representantes de la Provincia de Buenos Aires, 1822, vol. VII, p. 256.

18 Diario de Sesiones de la H. Junta de Representantes de la Provincia de Buenos Aires, 1822, vol. VII, p. 257.

19 Diario de Sesiones de la H. Junta de Representantes de la Provincia de Buenos Aires, 1822, vol. VII, p. 229.

20 Diario de Sesiones de la H. Junta de Representantes de la Provincia de Buenos Aires, 1822, vol. VII, pp. $256-257$.

21 Diario de Sesiones de la H. Junta de Representantes de la Provincia de Buenos Aires, 1822, vol. VII, p. 259.

22 Diario de Sesiones de la H. Junta de Representantes de la Provincia de Buenos Aires, 1822, vol. VII, p. 260.

23 Diario de Sesiones de la H. Junta de Representantes de la Provincia de Buenos Aires, 1822, vol. VII, p. 262.

24 Diario de Sesiones de la H. Junta de Representantes de la Provincia de Buenos Aires, 1822, vol. VII, pp. 587-589.

25 Diario de Sesiones de la H. Junta de Representantes de la Provincia de Buenos Aires, 1822, vol. VII, pp. 591.

26 Proyecto de decreto. Honorable Sala de Representantes de la Provincia, Buenos Aires, 1822. Recuperado de: https:// archive.org/details/proyectodedecret00buen

27 Diario de Sesiones de la H. Junta de Representantes de la Provincia de Buenos Aires, 1822, vol. VII, p. 154.

28 El ideal de unanimidad y la condena al faccionalismo fueron datos comunes en todo el mundo atlántico convulsionado por revoluciones desde fines del siglo XVIII, véase (Guerra, 1994; Rosanvallon, 2007).

29 Registro Oficial de Buenos Aires del año 1821, Buenos Aires, 1824, pp. 112-115.

30 El Centinela, $\mathrm{n}^{\circ}$ 35, 6 de abril de 1823.

31 Diario de Sesiones de la H. Junta de Representantes de la Provincia de Buenos Aires, 1822, vol. VII, p. 152.

32 La traición implicaba varias acciones, como matar al rey, formar alianza con enemigos para arrebatarle el reino, promover sublevación entre los súbditos, destruir imágenes hechas en su honor. Las siete partidas del rey Don Alfonso el Sabio, cotejadas con varios códices antiguos, por la Real Academia de la historia, 1807, t. III, pp. 537-542. La obra de referencia indispensable sobre el crimen de lesa majestad es (Sbriccoli, 1974).

33 Archivo General de la Nación, X, 13-3-6. Revolución de Tagle.

34 Archivo General de la Nación, X, 13-3-6. Revolución de Tagle.

35 Archivo General de la Nación, X-03-09-10. Gobierno. Nacional. 1820. Mayo- Diciembre.

36 Archivo General de la Nación, X, 13-3-6. Revolución de Tagle.

37 Archivo General de la Nación, X, 13-3-6. Revolución de Tagle.

38 Sobre las implicancias y consecuencias del fusilamiento de Manuel Dorrego véase (Fradkin, 2008; Di Meglio, 2014) 